graph should be. It is succinct, readable and reliable. The subject of the megaloblastic anaemias is one in which rapid advances have been made in recent years and there was a widely felt need for an authoritative summary of the present day position. This little book fills that need admirably. The authors discuss all the forms of the megaloblastic anaemias and have skilfully outlined the position of present-day research in this field. The book will be of value not only to the practising haematologist to whom it will supply a useful summary, but also to the general physician who wants to clarify his ideas in a difficult subject.

\section{THE BRITISH CONTRIBUTION TO MEDICINE}

By Dr. J. Jaramillo-Arango. Pp. xii +220 , with 45 illustrations. Edinburgh: E. \& S. Livingstone, Ltd. 1953. 25 s.

The author of this interesting book, Dr. Jaime Jaramillo-Arango, was Ambassador of the Republic of Columbia to Great Britain during the Second World War. Previously he had practised as a surgeon in Columbia and was Rector of the National Faculty of Medicine of Bogota. $\mathrm{He}$ is therefore a highly competent foreign observer of British Medicine whose knowledge of Great Britain has clearly made him very sympathetic to the aims and ideals of British Medicine.

The book opens with a historical survey of eminent British work in medicine and then, in succeeding chapters, proceeds to consider in detail six main subjects where British contributions have been particularly important. These are: the vaccine treatment of enteric fevers, the discovery of penicillin, the use of other antibiotics, the treatment of malaria, the discovery of the vitamins, and cancer research. The author sketches in the historical background of all these subjects and then describes in some detail the more recent advances in our knowledge of them. Although the main purpose of the book is to emphasise the importance of British contributions to medical knowledge, the author also provides a fair statement of the contributions made by workers in other countries. His style is attractive and the book is eminently readable.

\section{ULCERATIVE COLITIS AND ITS SURGICAL TREATMENT}

By Bryan N. Brooke, M.Chir., F.R.C.S. Pp. ix +147 , with 89 illustrations, many in colour. Edinburgh: E. \& S. Livingstone, Ltd. 1954. 37s. 6d.

The surgery of ulcerative colitis has undergone considerable changes in the last few years, and a monograph on the subject taking stock of these developments is certainly timely. Mr. Brooke brings to the task of writing such a work a very considerable personal experience of the disease and its surgical,treatment. To this he has allied a thorough survey of the relevant literature and a literary craftsmanship of a high order, so that the resulting volume is both comprehensive and eminently readable.

The evolution of surgical methods in the treatment of colitis is surveyed from appendicostomy to the modern combined ileostomy and colectomy or proctocolectomy. The technique of the latter operations is described in detail and the excellent results obtained by the author and by other workers are reported in full. It is clear that these apparently formidable procedures can now be carried out with a low mortality even in critically ill patients suffering from colonic perforation or massive haemorrhage. Conservative methods of colectomy with preservation of the rectum and anal sphincters with ileorectal or ileo-anal anastomosis are categorically condemned. Some surgeons may wonder if this condemnation is not too sweeping, for cases are occasionally encountered where the rectum is substantially normal and colectomy with ileo-rectal anastomosis gives an excellent functional result, at any rate for some years, but few will dispute that ileostomy must remain one of the keystones in treatment for most patients proceeding to surgery. One of the best sections in the book is, appropriately, that dealing with the construction and subsequent care of an ileostomy. The advantages of adherent ileostomy appliances of the Rutzen type are rightly stressed but attention is drawn to some of their imperfections.

The author has taken the opportunity presented by the pathological material derived from hiso colectomies and proctocolectomies to review the clinico-pathological features of ulcerative colitis. In describing the various morbid changes that may be encountered he attempts to classify cases of colitis into four quite distinct pathological entities; proctosigmoiditis, true ulcerative colitis, ileocolitis and Crohn's disease. It cannot be said that the evidence that these are separate conditions is at all convincing. Ileocolitis seems to figure much more largely in the author's experience than in that of most other gastro-enterologists; one effect of this book, however, will be to direct attention to the lower ileum in patients with colitis:

The monograph is lavishly illustrated, many of the figures being in colour. Most of the illustrations are excellent, but a few of the coloured plates of specimens and operative views, which must have added considerably to the expense of the book, are of very doubtful value, for they remain virtually unintelligible even after reading the legends.

Altogether this is an excellent work which should be most helpful to surgeons and physicians called upon to treat patients suffering from ulcerative colitis, even if they do not agree with all that they read in it.

$$
\text { J.C.G. }
$$

\section{PEPTIC ULCER}

By C. F. W. Illingworth, C.B.E., M.D., Ch.M., F.R.C.S.E., F.R.F.P.S. Pp. vii +287 , with 89 illustrations, some in colour. Edinburgh: E. \& S. Livingstone, Ltd., 1953. 42s.

There is nothing cut and dried about our 
knowledge of the group of diseases which we call peptic ulcer. A host of observations, and a neverending stream of patients have not yet shown the way to understanding. It is hard to look upon present modes of treatment with satisfaction when it is clear from the study of peptic ulcer that the peptic digestive process is only the conclusion of the causal sequence.

Professor Illingworth's book brings to the general reader, and to the specialist, the concept which the author has formed during a lifetime's interest in this subject. At all times his theme is orientated by reference to the literature; indeed, the book embodies a bibliography which ranges from the historical to the topical in a well-organised way which is as stimulating to the reader as the neat and clear text itself. Physiological discoveries of the last century, and the experimental methods of today are used to illustrate the hormonal and biochemical mechanisms of the stomach. Gastric analysis is firmly put in its place and the newer methods of study which are replacing it are fully reviewed. Recent additions to these have not been omitted in the larger task of publication; for example, the comment is included upon the estimation of quinine and of pepsinogen in the urine as methods of tubeless gastric analysis.

Less than half of the text concerns the surgery of peptic ulcer and most of this is a discussion of special forms of the disease which pose such difficulties for the surgeon; operative indications and complications are wisely stressed as of general importance, techniques are modestly presented as a personal choice. The facts learned from a follow-up of gastro-jejurostomy patients in the ulcer clinic held by the author and his colleagues have confirmed that some good results can be obtained with this simple procedure; the limited indications are suggested and, while we may not all agree, we should not disregard them from having a habit of performing gastrectomy. Dumping syndrome, failure to gain weight, a suspected tendency to develop pulmonary tuberculosis and other serious consequences of gastric resection are weighed and considered in the light of the favourable results. Most readers will find this fare is greatly to their liking, whatever their degree of interest in the subject. Physicians and surgeons alike will find their point of view presented with authority and understanding. No medical library will be complete without this monograph.

\section{H.H.G.E.}

\section{COMPRESSION ARTHRODESIS}

By John Charnley, F.R.C.S. Pp. xi +264 , with 208 illustrations. Edinburgh: E. \& S. Livingstone, Ltd. 1953 . $42 \mathrm{~s}$.

In introducing this book the author emphasizes that every surgical operation is a biological experiment and that a few observations in the human are often of more value than a large series of experiments in animals.
In the early chapters he examines the problen? of union of cortical and cancellous bone. He comes to the conclusion that compression has no part t田 play in the union of cortical bone but that if:stimulates rapid union of cancellous bone. Thos surgeons who have applied compression in arthro $\stackrel{\oplus}{+}$ desis of the knee after the method of Dr. Key and Mr. Charnley will probably all accept the fact that clinical union may be observed four weeks afte the operation and sometimes sooner. Mr. Charnlex now presents histological evidence of this rapiof union, which has been obtained by removing specimens of bone with a special tubular trephine $\overrightarrow{0}$ A lucid account of the histological pictures and the

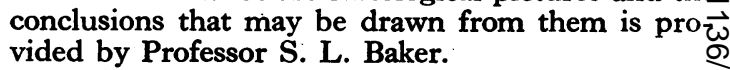

A chapter on "The Theory of Compression Arthrodesis' contains a survey of the possible factors contributing to such rapid union in arthro desis of the knee, including area of contact, immo bilization and compression. The effect of com $\omega$ pression on the activity of the osteoblast and osteoclast is also considered.

The evidence obtained from specimens of bonetr removed by the trephine certainly supports $\mathrm{Mr}_{0}^{0}$ Charnley's theory, but cannot be considered to prove it. The reviewer found himself constantly turning with relief from the enthusiastic writing of Mr. Charnley to the simple factual account of the histology provided by Professor Baker.

The second half of the book is devoted too practical account of the principles and methods $f$ arthrodesis of various joints in the limbs, partic larly the ankle and the hip. It is in this section of the book that Mr. Charnley is on more solid ground because of his clinical experience and fertileo imagination combined with mechanical ingenuity. के

The principle of central dislocation of the hip that he has developed is described together witho technical details of the operation and its application to the problem of the painful hip joint.

The standard of illustration in this book leaves. nothing to be desired. The text, however, is noto always of a high standard. A sentence such as 3 . 'All living organisms are self-regulating mechanisms' and Wolff's Law is a visible manifestation of it must not be allowed to pass on to the next edition. $\delta$ Another criticism that may be made is of $\mathrm{Mr}$. Charnley's use of the first person plural throughout the book. There seems to be no justification for the substitution of ' we ' for ' $I$ ' unless the respon- $\frac{}{0}$ sibility for the statements made is shared with other persons, but there is no indication that this is then case. In referring to an individual patient the statement that 'This Cup Arthroplasty has no 0 pain and does not use a stick' may be permissible N in casual discussion, but it should not appear in

There is little in this book that will not stimulate critical thought in the reader and therefore its publication was fully justified. It will be interesting, however, to see how Mr. Charnley's ideas will stand the test of time and practice in other surgeons' hands. 